\title{
Climate change, social dreaming and art: Thinking the unthinkable
}

\author{
Julian Manley and Wendy Hollway
}

\section{Beyond the Scientific Fact}

The problem of how people can accept the reality of climate change and its effects on our daily lives is central in climate psychology. Scientific facts have proved remarkably ineffective in leading to necessary changes in lifestyle required on both an individual and a social level. For many, the facts are either traumatic or unacceptable. The requirement posed by global warming to change people's deeply held desires for ever-increasing economic prosperity and the assumed concomitant wellbeing leads to shared and generalised disavowal and denial. In the world of climate change deniers or disavowers the status of scientific factual reality is a significant issue: the scientific facts backed by $97 \%$ of the scientific community are not 'fact-enough' for meaningful social change: information, debates, surveys, focus groups and suchlike fail to open the way to significant action. In the case of climate change we are in a zone of gut rejection: even if it is, it cannot be. Al Gore's 'inconvenience' (Gore 2006) is more than that: it is something so inconvenient that it cannot be countenanced.

Psycho-social approaches to climate change, therefore, tend to take a containing approach to people's fears, traumas and deep concerns. For example, Randall and Brown's (2015) 'carbon conversations' project provides practical and experiential psycho-social approaches designed to create contained spaces for reflection and transformation. Through conversation, according to Westcott (2016), there is a chance for denial and disavowal to be converted into hope and trust, without which climate anxieties are repressed and ignored rather than confronted. Such approaches have been positively evaluated by Büchs, Hinton and Smith (2015) who summarise the emotions that can be discussed through conversation related to climate change as fear and anxiety, grief, guilt, helplessness and feeling threatened in one's identity/status (Büchs et al. 2015, p. 622). It is through the careful containment of shared conversations that people are given an opportunity to be released from the isolation, loneliness, guilt and even horror that scientific facts point to. These conversations change the nature and quality of the climate fact through each person's relation to the facts. In a sense, the reality of the fact is given a potential for being re-experienced, almost as if it were not a factual entity in and of itself. Climate facts are thus subjectivised and their reality is found in the transactions between external and internal world experiencing.

This chapter concentrates on a different way of knowing, focusing on the shared visual and affective aspects of people's relationship to climate change. It uses the data from an art and social dreaming event to explore how the use of affect-laden images in a shared 'unconscious' context, hidden or unknown, can help us to recognize the reality of climate change. Social dreaming is a method that allows new knowledge to emerge in a gathering of people who share their dreams, associations and feelings together. The method creates a non-threatening, non-judgmental space where difficult thoughts and feelings can be expressed through images (Lawrence 2005; Manley 2014, 2018). In Social dreaming and the visual arts, the realm of worded communication is subsumed into a world of image and affect. Both involve what Donald Meltzer calls the 'poetry of the dream' whose role in thinking is that it 
'catches and gives formal representation to the passions which are the meaning of our experience so that they may be operated upon by reason' (Meltzer 2009 p.47).

According to Meltzer (2009[1984]) 'Dream life can be viewed as a place to which we can go in our sleep, when we can turn our attention fully to this internal world'. He uses the phrase 'dream life' to emphasise the kind of dreaming that goes on all the time, awake or asleep. The idea that dreams are part of our everyday existence was also an important aspect of Bion's concept of the unconscious (Ferrero 2002). The social dreaming matrix in its function as a container of dreams and associations in this way provides a space that enables more than a mere recounting and description of past dreams. It is, rather, a reliving of dreams, what Ferrero calls 'redreaming', a 'syncretic narrative mosaic' (Ferrero 2002, p 605) that brings the dreams back into present experience, thus creating a 'dream life'. It is to these internal worlds that the Social Dreaming method listens, using the waking recounting of night dreams and associations to them, supported by facilitating reverie in a containing space. 'The creative process of dreaming generates meaning that can then be deployed to life and relationship in the outside world' (Meltzer 2009[1984] p. 46). Meltzer is explicit about the central place of the aesthetic in psychoanalysis, describing his account of dream life as an attempt to formulate an aesthetic theory of dreams (Harris Williams, 2010 p. 8). In our social dreaming/ art event, the experience of engaging with the artworks was combined with the dreams in the matrix, engaging the participants in a presently shared lived aesthetic of dreams and associations that opened up a new space of creative thinking leading to new meanings. The way shared dreams can naturally combine with shared experiences of art resides in how both experiences are able to provide an affective filter for past experiences and current knowledge to be evoked, shared, reconsidered and reconfigured as new knowledge which is no longer past. The dreams are processed internally and shared externally - inside out - while the artworks are received externally and processed internally - outside in - and join the dreams in an eventual shared experience in the matrix. This inside-out/ outside-in flow of image and affects of the aesthetic experience can be compared to Guattari's identification of such a psycho-aesthetic process as 'processual complexity, with possibilities that are constantly developing' where the emphasis is on the present, 'not on the past' (Guattari, quoted in Ettinger 2002, p. 243, author's italics).

The artworks experienced by participants in this social dreaming event were curated by the arts organisation, Cape Farewell (www.capefarewell.com). Their mission - to mobilise climate change awareness through the medium of art - is based on the same belief that art is capable of effecting change by engaging people in the kind of emotional responses that fact-based interventions fail to do. This belief is difficult to establish systematically through research, a key problem being that dominant research paradigms are science-based, hence impose a non-congruent paradigm in relation to Humanities, art and culture. Epistemologically this problem is often conceptualised as the sciences and arts drawing on different types of knowing: rational/emotional, factual/aesthetic particular/holistic, logical/intuitive, explicit/implicit. Here we explore a paradigm that is congruent with art, culture and the Humanities.

\section{Social Dreaming and Climate Change}


The principles we are adopting here to inform Social Dreaming, contrary to the compartmentalisation that characterises scientific methodology, have the capacity to explore an indivisible experience; a different kind of knowing. In different psychoanalytically informed paradigms, these principles are referred to as affective, associative, rhizomatic or scenic. Psychoanalysis has provided an ontology that is comfortable with the non-cognitive realm, with dynamic, unconscious and conflictual forces. It understands aesthetic experience as outside the cognitively aware realm. Ehrenzweig (1967) theorised the apprehension of art as taking place at two levels, which he termed analytic and syncretistic, the latter being the indivisible experience. Social dreaming has these qualities but goes further by not being limited to the individual focus that has characterised much of psychoanalysis historically. It generates knowledges that go beyond the individuals who feature in the research design and constructs shared imagistic social collages of experiences that cannot adequately be put into words. The dreams, their associations and the affects embedded within them, become recognisable in social dreaming as images in a spontaneous, nomadic landscape, not as lines of cognition in words, thoughts and feelings. 'Nomadic' here refers to the Deleuzian account of concepts and creations that emerge without restriction or preconceived directions, ideas in constant travel and in ever-changing states of emergence (Deleuze and Guattari 1988). These reach into places of inarticulable knowledge - the realm of the 'unthought known' (Bollas 1987) - based on direct experience, that is poorly represented by consciously available climate change discourses.

From a largely humanities base, the idea of climate change as a 'hyperobject' emphasises this impossible-to-grasp nature of climate change. Hyperobjects - of which global warming is Morton's (2013) leading example - have an extension in time and space that makes them historically beyond the range of human cognition; they 'massively outscale us' (p.12). However, although the idea of global warming in its entirety cannot be accessed at a cognitive distance, it is 'right here in my social and experiential space' (2013 p.27), having a viscous quality: climate change 'sticks' to everything - the plastic food wrapping, the car journeys, heating the house, the microwave, the smell of bacon, waste disposal... Paradoxically, then, the hyperobject is also non-local because its local direct manifestations are not the hyperobject itself (although it is raining heavily again this is not 'global warming' that I feel directly). These characteristics require a different research approach than science and social science afford. A Humanities based research paradigm should produce different forms of knowledge. If our methods can access the 'unthought known' and the hyperobject of climate change, what does this look like and how can it be made accessible to wider culture?

\section{Design}

The design of the event was innovative It incorporated artworks into the dreaming experience: An hour in the evening was spent viewing specially curated ${ }^{\mathrm{i}}$ artworks, which made some reference to the effects of climate change. They included visual images, objects, texts, filmed performance poetry, sculpture and pottery. This research design enabled us to look at the part played by the artworks in the dreams and dream associations that emerged in the Matrix. The participants were climate activists artists, scientists, researchers, and practitioners - people who face the threat of climate change on a continuous basis. 


\section{Context and Process}

On $13^{\text {th }}$ October 2017 sixteen participants gathered at a farm in Dorset, where in the surrounding barns there were climate-focused artworks from the Cape Farewell archive. On the first evening, the purpose of the event was outlined and participants were invited to spend an hour sharing and engaging with each other in the context of the farm buildings, where new social and aesthetic spaces were created, 'transitional' spaces in the Winnicottian sense (Winnicott 1991). Next morning, the Social Dreaming Matrix was convened and one of the two 'hosts' (the common term for facilitator in social dreaming events) - opened with the standard question 'what is the first dream?' This question deliberately emphasises the dream, not the dreamer, reflecting the fundamental claim of the method that its elicitation of associative thinking goes beyond individual experience and meaning to produce a wider, multilayered knowledge that we might call socio-cultural. This approach helps us to reject the compartmentalisation, reduction and consequent stripping of affective meaning typical of the scientific approach, which increasingly is at odds with the dawning of the age of the Anthropocene, and fashion something more in line with the Gaian principle of indivisibility (Lovelock and Margulis 1974).

During the process of the social dreaming matrix, conditions for reverie (the waking dreaming state that affords associative thinking) are carefully created: low lighting, quiet and a 'snowflake' seating pattern that discourages face-to-face engagement. These features help associations, images and ideas to emerge in place of facts, opinions, argument and cognition-based interactions. The matrix is followed by a facilitated post-matrix discussion that provides a space for a more cognitive mode of reflection. Both are recorded, and the ensuing transcription is used in analysis by the researchers.

\section{Sequences of Association}

To provide familiarity with the images and associated ideas that make up the matrix collage, we present an abbreviated chronological treatment of the first half of the matrix which, rather than being simply descriptive, traces a sequence ${ }^{\mathrm{ii}}$ that glimpses the passage of ideas from a modernist machine age of fossil fuel consumption through turbulent and destructive change to an imagined post-anthropocentric regeneration of the earth. This 'historical' sequence is salient in Couze Venn's (2018) After Capital, which situates climate change as central to converging world crises of capital, manifest in 'the global economy, the environment, the depletion of non-renewable resources, increasing violences and the break-down of social cohesion'. These 'threaten a perfect storm in the near future' (Venn 2018, p1). Given that all the participants are living through these changes; given that there is not something sealed off called 'global warming' or 'climate change', how did this show up in the matrix if it did at all? The social dreaming method claims to capture something sociocultural. The following analysis suggests that it did.

Gordon Lawrence, the inventor of Social Dreaming, believed that the first dream presented in a matrix was important in that it acted as a thematic forerunner to the whole collage sequence (Lawrence 2005, p.15). The first dream went as follows:

I remember hearing that a friend's Great Aunt Vera was driving and that she shouldn't because she is so frail and I had to do something about it, but I didn't know where she lived, apart from the fact that it was in Devon. So I 
went to a local post office store and asked the lady there if she could help. She said she was bound to know someone who could track her down. She went into the back office in the back of the shop and came out again and said "Sorry, we haven't been able to find Vera, but I believe she isn't driving, but rowing down a river". I said "Vera? Rowing down a river? She's far too frail for that!" Apparently the way she had done it was she had an inflatable snowman in the bow of the boat with two ropes attached to it, and if she pulled the snowman forward and let it go, it sprung back and rowed the boat... end of dream.

Let us treat Great Aunt Vera and her activities as a metaphor for humanity on a frail planet: the name signifies wisdom, age, experience and feminine gender - truth (Vera), generation (Aunt) and importance (Great). Driving references the machine age and fossil fuel consumption, which of course is alarming for one so frail. The dreamer 'had to do something' to stop this driving. Devon references a part of the UK where nature is unspoilt and local populations value it; the post office lady is part of a community where people still communicate, support each other. Perhaps the back office is where a different kind of knowing can be accessed, in contrast to the monetised transactions of the front counter. The information is only partially successful: Vera is not within their sights (perhaps this refers to how hard it is to pin down global climate change) but local knowledge has come good: she/the wisdom of old humanity is transformed, discarding machine age transport and accomplishing something more suited to youth than age, a result of ingenuity and natural energy. There is also an implication that a natural force can 'bounce back' when captured by humans (ropes) or that the planet can bounce back once carbon is under control. Great Aunt Vera is transported by ecological methods, borne along on water rather than tarmac. The snowman references the snow that is perishing at the earth's poles; inflatable (what is inflated? Claims of snow melt?) and vulnerable.

So the first dream reveals, in fractal fashion, a climate change scene: planetary frailty and wisdom, natural resources and technical ingenuity, obsolescence and innovation, human responsibility, community and concern, not yet tracked down but knowledge from the 'back'.

Water was a recurrent theme throughout the matrix; the two dreams following 'Great Aunt Vera' involved water borne transport - windsurf and yacht. In both dreams a storm/rough sea/big wind figured. In the second of these the defunct status of machine transport figured in 'hulks of buried helicopters' below the sea. On one hand, a high wind meant that 'the boat is sailing along at incredible speed' but there is ambivalence 'I even had the engines on as well in order to increase the speed, but then thought "that's stupid" and switched the engines off, the helicopters were still there'. Just because fossil fuel based transport is no longer necessary, doesn't mean to say that people aren't still wanting to use it - for extra and unnecessary speed. Soon followed dreams of 'a crappy one carriage train' that had already left the station and 'a cartoon airplane face up in the water'; then immediately another image of defunct machine age transport: a Boeing 747 with no wings or tail, parked on the road, taking up a lot of room but unnoticed by people, a detail that references how taken for granted fossil fuel based transport is even when it is blatantly dysfunctional and wrongly situated. 
Segued from the theme of transport came a dream that got to the heart of climate change threat: travelling by plane and car along hot and dusty routes, to the funeral of Mother Earth. But not empty handed: carrying a large brown nut, which was meant to be delivered there. It was in a white bag with 'palms' printed on the side. The nut is a seed, symbol of regeneration and the capacity of nature to carry on. Likewise a golden haired boy keeps turning up, for example at the airport; a symbol of the responsibility of an older generation to keep faith and deliver the hope of the earth's survival, a symbol that recurred many times, expressed as young women, young employees, a baby in a pushchair, a group of students and a toddler.

The theme of danger and disaster was continued in further dreams with Alpine avalanches killing unconcerned tourists in Wales and a nurse offering an inadequate remedy to a man 'completely full of water'. There followed an association to 'water water everywhere' (usually connoting 'not a drop to drink'). The water images multiply in the condensed fashion of dream images: flooding, sea level rise and drinking water scarcity resulting from drought. Eventually we are led to an image of water cleansing a turning globe, getting rid of 'us', the human beings responsible for the damage.

\section{Expansion}

At this stage of the social dreaming matrix, nearly half an hour in, the gentle chronological linearity in the matrix - which mirrors the sense of history that brought us from the taken-for-granted progress of the fossil fuel era to the current era of negative consequences - is challenged with a dream where the dreamer hits a signless sign post 'right between the eyes'.

I was walking and a lamp post post suddenly hit me between my eyes. [...] It wasn't a lamp post actually, it was more like a sign post, just a post without a sign on it.

This brief dream is an ironic wake-up call which plunges the matrix into deeper reverie in order to 'find the way' symbolised by the signless sign post. As a transition into this new direction, there is a realisation within the matrix that the issue of climate change has gone as far as it can in the old direction. A hit needs to be understood somehow through the body - 'right between the eyes' (the 'third eye'?), which connotes sudden insight. A series of four references to the body immediately ensues:

(1) I had the power to rearrange the body... (2) This is bringing up this line from Boris Johnson he said about clearing away the bodies... (3) My body dictates the texture and quality of my dreams... (4) If you can't sleep ... you pour cold water on your feet and legs, just that part of your body...

The matrix then launches into a rhizomatic series of associations that combine the artworks and the dreams and associations, thus breaking up the general linearity of the matrix. A renewed emphasis on the body reassesses the role of affect, that is to say knowledge that is felt by the body before it is thought. The matrix expands into creativity, a new energy, by offering an alternative to fossil progress, which, as represented in the early references to machine transport, is the cause of climate change. The alternative was hinted at in the opening dream magic of Great Aunt 
Vera's boat, which is referred to once again in this new rhizomatic section of the matrix:

Energy repelling energy reminds me of Aunt Vera's snowman and the peculiar, magical form of motion.

The way the matrix is enabled to discuss alternative ways of perceiving and feeling human knowledge, described here as 'energy', is precisely through a combination of dreams, artworks, associations and affect, which we analyse below.

\section{Data Analysis and the Rhizome}

Data analytic principles need as much modification to be suitable to our purpose as did the approach for generating the data: not linear, not broken up into discreet entities, respecting the bizarre-seeming, the multiple and uncertain, sensing the affect, following the associative unconscious through links and gaps. This 'rhizomatic' analysis is guided by Deleuze's image of a "rhizome" as a randomly self-selecting set of interconnected image-affects that pulse in intensity at a given moment of perception. Instead of lines of thought, Deleuze and Guattari posited the concept of the rhizome to describe a "circulation of states" $(1988$, p. 21$)$ that have no predestined direction, no centre, no hierarchy or guidance from any authority. This description reflects the structure of the collage of associations of the social dreaming matrix, its fluidity and the way it is created, namely through spontaneous expression of dreams, affect and associations of participants.

In this view, the chronological 'beginning' is not necessarily the best place to start the analysis, although our method is limited by the irreducible linearity of language that forms our transcript, which must be read in the context of time passing. We have shown above how a certain sequentiality of associations led on from the opening dream and how this can be justified both in terms of the nature of the interactions and the chrono-historical story of the journey of fossil-led progress. In what follows, we delve into the body of the matrix and show how linearity gives way to rhizomatic configurations.

At this stage of the matrix, the contributions seem to pass a syncretic threshold of expression: the dream images and associations begin to fuse and merge with the artworks. At the same time, the dream images from the beginning of the matrix also re-emerge at this point with a different and greater intensity than when they were first presented to the matrix. It is at this stage that the complexity of the affective interchanges of the matrix appear to mirror the inherent complexity of climate change as a hyperobject, where, in rhizomatic fashion, the earlier experience of witnessing the artworks is ignited in the thoughts and feelings of the here and now of the social dreaming matrix. As this merger occurs, there is a sense that the artworks, as they exist in the minds of the participants in the matrix, become available to participants in much the same way as the dream images are functioning for and in the matrix, thus seemingly acquiring a dreamlike quality and becoming a seamless part of the increasingly complex collages of images that form the thinking and affective space of the matrix.

As the matrix proceeds knowledge emerges in an implicit manner reminiscent of Polanyi's 'tacit knowledge' (1967) or Bollas' 'unthought known' (1987) or Bohm's 
'implicate order' (1980). These theoretically diverse terms all indicate a similar preoccupation with what is hidden from our cognitive function, what in psycho-social studies is sometimes referred to as knowledge that lies 'beneath the surface' (Clarke and Hoggett, 2009), from some less-than-conscious space in the shared arena of affect that is the social dreaming matrix. These thoughts and affects are extremely complex as they emerge from that implicate, unthought place, where the multiple reality of complex systems - the hyperobject of climate change - can be made known through the sharing of hinted at and beneath-the-surface knowledge. It is not the finer detail that drives the message home, rather it is the accepted wholeness of an intuited sensation of resonating congruity and affect shared among the temporary friends who form the matrix, where awareness of the rhizome of affects does not demand or presuppose a cognition of its every node and movement.

\section{A Pulse of Intensity and the Creativity of the Rhizome}

At the half hour point of our social dreaming matrix there is a significant shift in the development of the rhizome of affect that is being shared as the dreams and artworks unexpectedly converge. The artwork that emerges at this moment in the matrix is the following by David Buckland, which juxtaposes a hugely magnified image of a coccolithophore, (a single cell phytoplankton whose calcium carbonate structure is the substance of all chalk cliffs), with a scientific description by the scientist IglesiasRodriguez of a carbon-based process in seawater that contributes to global warming.

\section{INSERT IMAGE HERE}

Fig.1 Caché. Detail from artwork by David Buckland and Dr. Deborah IglesiasRodriguez www.bucklandart.com/art/cache-2012/

NOTE FOR PUBLISHER: "image should be used as a bleed. We can ask the artist, David Buckland if needs reformatting for size"

The beautiful image of the coccolithophore that is embedded in the artwork is under normal circumstances invisible to the naked eye: it cannot naturally be seen with the eyes in our heads. We might know it is there (and this artwork provides us with such knowledge), or we might intuit it, and this reminds us of the signless sign post, where not everything can be seen and therefore it is unclear what direction one should take. To 'see' what is hidden in this requires the artwork. To make sense of it and discover a 'new direction' requires the fusion of the artwork into the collage of images of the matrix.

In their inscrutability, the words provide a false sense of direction. The image that cannot be seen is nevertheless revealed through magnification and displayed as an artistic image rather than an illustration of science; the scientific text, presumably logical, rational and explanatory, is also displayed as art. It can be 'seen' and yet remains indecipherable to the non-scientist despite the aim of science to verbalise with absolute clarity. In different ways, neither image nor text can be 'seen'. Ironically, and to make the point, the text is completed by a winking emoji (itself an 
image directly linked to an emotion, rather than a word) and the line "Do you have a headache now?" This speaks to Morton's idea that 'the more data we have about hyperobjects, the less we know about them' (2013 p.180). Conversely it might also suggest the possibility that the fewer facts at your disposal, the more you know. This is the case of the image in the artwork. The fact of the science is replaced by an aesthetic experience. It is through the image as an artwork rather than as fact that participants come to 'know'.

The turning point that connects the dreams to the artwork is when one of the participants recounts a dream where he is hit 'right between the eyes', mentioned above. From this moment the dreams and artworks are fused within the body of the matrix. In the dream offered at this stage, an adult is climbing up the stairs of a tall tower-like building, 'entrusted with the care of some toddler'. They both manage to climb the insecure stairs despite the dangers of a lack of bannister and gaps that must be bridged with ladders. All of this is achieved with 'quite a feeling of omnipotence'. In this dream, the success of the climb and the handing down of experience and knowledge through the generations as represented in the 'toddler' elicits a sense of superior human conquest in overcoming obstacles. It is the ultimate example of humankind's rise (up the stairs) and unparalleled success in defying the odds (the gaps) along the path of progress that the matrix has been concerned with until this moment. The dream is immediately followed by the following association to the artwork:

The image of the stairs reminds me of the image of the carbon molecule (sic) on the barn wall outside, incredibly intricate and beautiful structure, which I found very moving, and then I noticed one of the ladders on the stairs was broken or only half formed in this microcosmic molecule, and I was wondering what kind of stresses that expresses or whether they were never perfectly formed for some reason. But that image of the broken stairs reminded me of the imperfect but perfectly beautiful cellular structure.

In this association that is explicitly connected to the previous dream, artwork and dreamwork come together to uncover the hidden and mysterious beauty of the 'molecule' that can potentially be found in the dream structure of broken stairs winding their way upwards. Where in the dream we are left with a sense of conquest (omnipotence), now our attention is drawn to something 'incredibly intricate' and 'beautiful'. Importantly, this perception of the hidden (made visible through magnification), is described as 'very moving', an aesthetic experience. So here we have a description of felt affect and its embeddedness in the visual that is fundamental to the Deleuzian rhizome. Instead of broken stairs being gaps to overcome as in the dream, the 'broken or only half formed' stairs in the perception of the image in the artwork are inducements to affective reflection, a questioning of the kinds of 'stresses' that might have brought these about. The joining of the associative affect of this reflection on the artwork with the telling of the dream brings into question the conquering tone of the dream noted above, and presents a possibility of some other direction to take: maybe inwards (as in a magnification) rather than outwards/upwards, as in the dream. It provides a new language and sign for our signpost. 
As a result of this new direction, the matrix can move on to a different, creative and affective pursuit of knowledge. This knowledge is summarised in the following reference to 'energy' as part of the new development of the associations provoked by the fusion of artwork and dreamwork:

That reminds me of images of molecules and that most of the molecule or atom is space, there's nothing in it except energy.

This 'energy' appears to suggest an invisible (now acceptable in the thinking of the matrix) binding agent between disparate elements that is reminiscent of the Deleuzian concept of affect as a continuum between objects that increases/decreases in intensity and that holds elements together in relationship according to this continuously fluctuating pulse of affect. The energy evoked in the matrix and stimulated by the thinking and feeling process of the dreams and the experience of the artworks can be thought of in terms of Deleuzian 'duration' that operates between states of affect in rhizomatic relationship. These states are, as Deleuze comments with reference to Spinoza, 'affections, images or ideas [which] are not separable from the duration that attaches them to the preceding state and makes them tend towards the next state' (Deleuze 1988, p. 49). The establishment of the rhizome that constitutes the structure of this non-linear interconnectivity between the dream images that now merge with the artworks is 'seen' in the embodied mind of each participant. This effect is exemplified in the following contribution that makes an association with the first dream of the matrix; in other words the structural pattern in the mind has become a rhizomatic connection rather than a sequential one, linked by affect or 'energy':

Energy repelling energy reminds me of Aunt Vera's snowman and the peculiar, magical form of motion.

Once established in this new mode of reflection, the matrix is able to see the combination of affective and associative thinking as more than theoretical and as actually defining the embodied process of the matrix itself in the following reference to the snowflake configuration of the here and now of the matrix:

It's funny because it looks really close but also a feeling of space like the atom you were talking about: the way of talking and sharing in the now.

A further association describes this space of new affect which is contained in the created rhizome of the matrix as being a safe space for thought and, crucially, a space where the 'huge' can be contemplated:

A lot of dreams have involved catastrophes and disasters, and things going wrong, but always as us the observers in a safe place, which is interesting because that sort of feels like what we're doing here, we're talking about or thinking about a huge issue but feeling fairly safe.

The ability to talk of huge and disturbing issues in sufficient safety suggests that social dreaming and art did indeed create a space of understanding of the Mortonian hyperobject. 


\section{Conclusion}

At the start of this chapter we set out to discover whether the combination of social dreaming and the experience of artworks related to a theme of climate change could provide a means of capturing a shared unthought known of climate change, capturing its enormity and complexity in such a way as to make the possibility of effective and meaningful action a genuine possibility. We posited that scientific facts were not effective for change, as demonstrated in the failure to elicit lifestyle and social changes that would help to stop and reverse climate change, despite overwhelming scientific factual evidence that should leave no room for doubt. We suggested that we needed a new epistemology, a new way of expressing and perceiving knowledge, and our study has pursued the idea that such a knowledge may be brought into shared consciousness through social dreaming and art.

In investigating social dreaming and art as a means of reconfiguring knowledge, our material has shown the utility of re-imagining a new sense of 'fact', moving from a bare, reduced raw fact of science to what is meaningful to participants in the matrix. The latter is like a felt truth, where the eventual knowledge is sensed through affect and made into a different 'fact' through the sharing and relatedness of the participants' experiences of the artworks and social dreaming. The nature of the hyperobject is not that it is free of facts but on the contrary it embraces too many compartmentalised facts to cognitively capture, understand and eventually to act upon. It is truly complex. It cannot be seen. In this way we unpack Morton's philosophical take on the difficulty and yet the need to understand climate change as a hyperobject. The hyperobject, we have pointed out, is felt in aspects that are associated and yet not directly connected to the scientific fact of climate change. These associations of the social dreaming matrix are no less true than the facts of the hyperobject but they present these truths in a way that can be seen and felt. An example of this in the matrix was the creation of a 'fact' of the 'energy' that holds ecological complexity together. The identification of this energy made it possible for participants to understand how each separate aspect related to climate change can assume a connected unfragmented whole. It made the interconnectivity of Gaia theory more tangible. An important pathway to this grasping of the hyperobject was in the act of social dreaming itself, which, we have suggested, is a practical method of 'redreaming' night time dreams and connecting to 'waking dreams' that are better able to give meaning to the hyper and the macro. In doing so, we have drawn on Meltzer's and Bion's theories of the dream world as being omnipresent, as relevant to waking life as sleep. Meltzer and Deleuze and Guattari have linked the creative imagination to the aesthetic experience. We saw how the aesthetic experience enabled the social dreaming matrix to become complex in rhizomatic intensity mirroring the complexity of climate change and providing the conceptual and experiential shift in knowledge from linearity to complex systems that can be experienced in the here and now of the social dreaming matrix. Importantly, therefore, we conclude that it is through this associative thinking in a shared context that new ways of knowing are created, an experience of felt knowledge nurtured into existence through the combination of social dreaming and art, which enables us to apprehend climate change in the macrocosmic way that it demands and gestures to an imagined and almost hopeful postanthropocentric vision. 


\section{References}

Bion, W.R. (1962b) A theory of thinking, International Journal of Psycho-Analysis, 43, 306-310.

Bion, W. R. (1970). Attention and interpretation. London: Karnac.

Bohm, D. (1980). Wholeness and the implicate order. London: Routledge.

Bollas, C. (1987) The shadow of the object: psychoanalysis of the unthought known. London: Free Association Books.

Buchs, M., Hinton, E. \& Smith, G. (2015) "It helped me sort of face the end of the world": The role of emotions for third sector climate change initiatives, Environmental Values, 24, 5: 621-640.

Clarke, S. and Hoggett, P. (eds.), Researching beneath the surface. London: Karnac.

Deleuze, G. (1988). Spinoza, practical philosophy. San Francisco: City Lights.

Deleuze, G.and Guattari, F. (1988). A thousand plateaus. London: Continuum.

Ehrenzweig, A. (1967[1970]) The hidden order of art. London: Paladin.

Ettinger, B.L. (2002) From transference to the aesthetic paradigm: a conversation with Félix Guattari, In Massumi, B. (Ed.) A shock to thought. London: Routledge, pp. 240-246.

Ferrero, A. (2002) Some implications of Bion's thought. The waking dream and narrative derivatives. The International Journal of Psychoanalysis, 83(3), pp. 597607.

Gore, Al (2006) An inconvenient truth, film. USA: Lawrence Bender Productions.

Harris Williams, M. (2010) Bion's dream: a reading of the autobiographies. London: Karnac.

Lawrence, G. (Ed.) (2003) Experiences in social dreaming. London: Karnac.

Lawrence, W. G. (2005). Introduction to social dreaming. Transforming thinking. London: Karnac.

Lovelock, J. and Margulis, L. (1974) Atmospheric homeostasis by and for the biosphere: the Gaia hypothesis. Tellus XXVI.

http://www.jameslovelock.org/atmospheric-homeostasis-by-and-for-the-biospherethe-gaia-hypothesis/

Manley, J. (2014) Gordon Lawrence's social dreaming matrix: background, origins, history and developments. Organisational and Social Dynamics Vol 14/2 2014 
Manley, J. (2018). Social dreaming, associative thinking and intensities of affect. London: Palgrave Macmillan.

Meltzer, D. (2009) Dream life. London: Karnac.

Morton, T. (2013) Hyperobjects: philosophy and ecology after the end of the world. Minneapolis: University of Minnesota Press.

Morton, T. (2010) The ecological thought. Cambridge Mass: Harvard University Press.

Polanyi, M. (1967) The tacit dimension, New York: Anchor Books.

Randall, R. and Brown, A. (2015). In time for tomorrow? The carbon conversations handbook. Surefoot Effect.

Venn, C. (2018) After capital. London: Sage.

Westcott, G. M. (2016) The role of subjective factors in local authorities' action on climate change in South West England. PhD, University of the West of England. Available from: http://eprints.uwe.ac.uk/28966

Winnicott, D.W. (1991) Playing and reality. London: Routledge.

\footnotetext{
${ }^{\mathrm{i}}$ Curated by David Buckland on behalf of Cape Farewell.

ii Although the idea of a linear sequence is antithetical to our conceptual framework, there is a rationale for proceeding in this way, namely that the matrix proceeds by associations. The sequence is not always linear, as we discuss, but there is a sequence, which necessarily begins in linearity at the start of the matrix. At a later stage in the matrix that linearity gives way to rhizomatic structures.
} 